2018

\title{
Clinician, Educator, and Student Perceptions of Entry-level Academic Degree Requirements in Occupational Therapy Education
}

Whitney M. Lucas Molitor

University of South Dakota

Ranelle Nissen

University of South Dakota

Follow this and additional works at: https://encompass.eku.edu/jote

Part of the Occupational Therapy Commons

\section{Recommended Citation}

Lucas Molitor, W. M., \& Nissen, R. (2018). Clinician, Educator, and Student Perceptions of Entry-level Academic Degree Requirements in Occupational Therapy Education. Journal of Occupational Therapy Education, 2 (1). https://doi.org/10.26681/ jote. 2018.020102 


\title{
Clinician, Educator, and Student Perceptions of Entry-level Academic Degree Requirements in Occupational Therapy Education
}

\begin{abstract}
Entry-level occupational therapy degree requirements have varied since the establishment of the profession. Currently multiple degree paths exist. There are cited benefits for a multiple degree path system; however, barriers also exist. Most notable among these are confusion among recipients of services and other health care providers. As other healthcare professional programs have transitioned to a single point of entry at the doctoral level, occupational therapy, until recently, had not yet made this change. A nationwide online survey was used to assess perceptions of the entry-level doctorate. Participants included current occupational therapy practitioners (clinicians or educators) and students in entry-level occupational therapy or occupational therapy assistant programs. Results indicated decreased awareness of the benefits of an entry-level doctorate and suggested that the majority of occupational therapy practitioners, educators, and students surveyed were in favor of an optional entry-level doctorate. Fewer respondents believed that the doctorate should be required for entry-level competence. Education among current occupational therapists and occupational therapy students regarding the benefits of a mandatory entry-level clinical doctorate would be beneficial as the profession moves towards this as the mandated degree. Future research should address to what extent experiential learning, carried out during a doctoral rotation, increases student preparation, as well as how these experiences influence clinical practice and scholarship.
\end{abstract}

\section{Keywords}

Clinical doctorate, history, survey, accreditation

\section{Creative Commons License}

(c) (i) ()

This work is licensed under a Creative Commons Attribution-Noncommercial-No Derivative Works 4.0 License.

\section{Acknowledgements}

The authors wish to acknowledge Michelle Holbeck, Riley Johnson, Alaina Meyer, and Whitney Redler who were occupational therapy students at the time of this research for their role involvement in this research. 


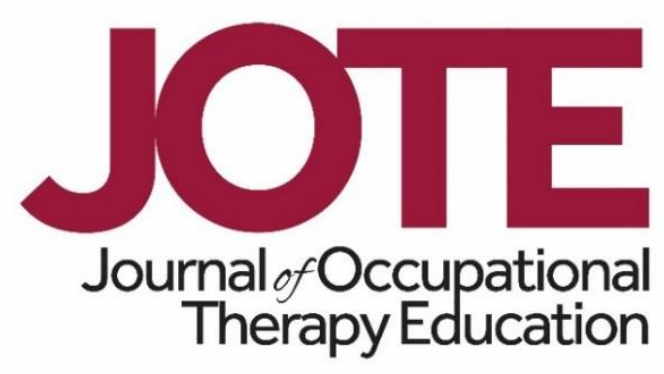

Volume 2, Issue 1

\title{
Clinician, Educator, and Student Perceptions of Entry-level Academic Degree Requirements in Occupational Therapy Education
}

\author{
Whitney Lucas Molitor, OTD, OTR/L, BCG and Ranelle Nissen, PhD, OTR/L \\ University of South Dakota \\ United States
}

\begin{abstract}
Entry-level occupational therapy degree requirements have varied since the establishment of the profession. Currently multiple degree paths exist. There are cited benefits for a multiple degree path system; however, barriers also exist. Most notable among these are confusion among recipients of services and other health care providers. As other healthcare professional programs have transitioned to a single point of entry at the doctoral level, occupational therapy, until recently, had not yet made this change. A nationwide online survey was used to assess perceptions of the entry-level doctorate. Participants included current occupational therapy practitioners (clinicians or educators) and students in entry-level occupational therapy or occupational therapy assistant programs. Results indicated decreased awareness of the benefits of an entrylevel doctorate and suggested that the majority of occupational therapy practitioners, educators, and students surveyed were in favor of an optional entry-level doctorate. Fewer respondents believed that the doctorate should be required for entry-level competence. Education among current occupational therapists and occupational therapy students regarding the benefits of a mandatory entry-level clinical doctorate would be beneficial as the profession moves towards this as the mandated degree. Future research should address to what extent experiential learning, carried out during a doctoral rotation, increases student preparation, as well as how these experiences influence clinical practice and scholarship.
\end{abstract}

\section{INTRODUCTION}

Dynamic changes in healthcare practice, reimbursement, and service delivery require healthcare professionals to demonstrate competence that aligns with contemporary society. Clinical skills rooted in knowledge and evidence must be combined with skills in research, management, advocacy, and others (Accreditation Council for Occupational Therapy Education [ACOTE], 2012). The profession of occupational therapy recognizes 
these skills as foundational to present-day service delivery and in doing so have created an avenue to obtain advanced skills through doctoral preparation. A clinical doctorate in occupational therapy, hereafter referred to as the OTD, may provide opportunities for occupational therapists to be at the forefront of healthcare practice, policymaking, and research. Despite these benefits, barriers to the recent mandate for doctoral preparation remain an area of uncertainty within the profession, meriting research that explores perceptions of entry-level degree requirements.

The American Occupational Therapy Association (AOTA) Board of Directors stated that by 2025 the profession of occupational therapy should act to transition to a doctorallevel single point of entry (American Occupational Therapy Association [AOTA], 2014). Only recently has ACOTE mandated that all programs must make plans to transition to an OTD by 2027 (ACOTE, 2017b). Despite degree requirement being a frequent topic of conversation in the profession, the new mandate has added to the already present uncertainty regarding the direction occupational therapy education is moving (AOTA, 2014). Not all within the profession agree with the new mandate, as evidenced by the discussion topics undertaken on listservs and online chat forums. It remains clear, however, that the profession needs prospective occupational therapists to become "future leaders, who are able to determine best practice through research evidence, become best educators who can maintain and heighten standards of educational excellence, and become best practitioners able to understand negotiating systems and contribute to policymaking" (Fisher \& Crabtree, 2009, p. 659).

\section{LITERATURE REVIEW}

\section{History of Occupational Therapy Education}

Requirements to obtain an entry-level occupational therapy degree have varied throughout the profession's history. Vast modifications in occupational therapy educational and degree requirements have occurred over the years (Brown, Crabtree, $\mathrm{Mu}, \&$ Wells, 2015). Accreditation has served to publicly highlight integrity and quality within the profession as a means of promoting confidence within educational communities and among recipients of occupational therapy services (ACOTE, 2017a). Carried out through professional, non-governmental organizations, standards are established and modified periodically to meet the changing needs of the profession. Minimal qualifications for occupational therapy education are depicted through these required standards that serve to provide value to the public, the profession, students, and institutions of higher education. Accreditation in occupational therapy education "requires institutions and programs to examine their goals, activities, and achievements; to consider the expert criticism and suggestions of a visiting team; and to determine internal procedures for action on recommendations from the accrediting agency" (AOTA, n.d., para 5).

The first set of educational standards in 1918 required a ten-week program that focused on leisure and recreational activities (ACOTE, 2017a). Within the same year, these standards were revised to better align with the medical model. Since that time, the profession has seen paradigm shifts ranging from moral treatment, the medical model, 
and occupation-based practice (Andersen \& Reed, 2017). With each shift, new standards have emerged, requiring a unique skillset to meet the demands of the time.

In 2006, Griffiths and Padilla reported, "occupational therapy education is in the midst of an evolution in regard to clinical education" (p. 548). Development of these changes initiated as far back as the mid 1960's when occupational therapy education established the baccalaureate degree as the official entry-level professional degree. At that time, AOTA maintained post-baccalaureate certificate programs, introduced education for occupational therapy assistants, and initiated entry-level master's degree programs (Colman, 1992). Thus began the theme of multiple-entry routes to certification for occupational therapy. Supporters of the multiple-entry-route argued the system was well designed and were concerned about drastically changing the existing educational system. However, those opposed to multiple-entry-routes feared students would be less prepared for practice, and argued the need to continue development of the profession's values and body of knowledge through research (Colman, 1992). Impetus for these changes included a drive for clinicians to be more involved in community-based practice, program development, and obtain a more expansive knowledge of concepts within the field (Barrett, 2000).

Beginning in January of 2007, ACOTE began to offer accreditation to postbaccalaureate programs exclusively, ending the ability of new occupational therapists to gain licensure with a bachelor's degree (ACOTE, 2017a). Today entry-level occupational therapists must obtain either a master's or doctoral degree in order to qualify for licensure (AOTA, 2014). Increasing complexities of clinical diagnoses, opportunities for non-traditional service delivery, and concerns regarding maintaining equivalency with other healthcare professionals have once again prompted discussion related to entry-level degree requirements.

Today the profession celebrates 100 years in the field. More than ever, the demand to meet society's changing needs, to be competitive with other healthcare disciplines, and to advance the profession is evident. The original Centennial Vision stated that "occupational therapy is a powerful, widely recognized, science-driven, and evidencebased profession with a globally connected and diverse workforce meeting society's occupational needs" (AOTA, 2006, para.1). Reaching this landmark, the profession now has an initiative focusing on making occupational therapists accessible, collaborative, and effective leaders aimed at guiding the profession's strategic priorities, maintaining continuity, and preparing the field to meet the obstacles of the evolving health care system (AOTA, 2016). With this vision, occupational therapists utilize knowledge and leadership rooted in theory to competently meet the demands of complex settings, health care models, and clientele (Wells \& Crabtree, 2012).

\section{Degree Requirements in Other Rehabilitation Professions}

Other rehabilitation professional programs have previously transitioned to degree requirements mandating a doctoral degree. Physical therapy faced similar challenges as those cited currently in the occupational therapy literature regarding degree transition. As early as 1992, post-professional doctoral programs deemed 'transitional' 
began to offer doctoral degrees to current physical therapy practitioners. By 1999, all entry-level programs were required to be at the master's level, with rationale for this centering on the changing needs required for clinical practice and the accompanying complexities of varied clinical settings. As physical therapy moved towards a doctorate requirement, opponents cited lack of trained faculty, shortages of therapists, degree confusion, degree inflation, and uncertainty in healthcare reform as reasons against this transition (Plack \& Wong, 2002). Conversely, those in favor of this transition felt that it would increase public recognition of the profession and lead to autonomous practice, with the ultimate goal of increasing independent practice through decreased reliance on physician referrals (Brudvig \& Colbeck, 2007). Around this same time, the first Clinical Doctorate in Audiology (AuD) programs opened, emphasizing research and clinical experiences (Koehnke, Besing, Shea-Miller, \& Martin, 2004). Public perception regarding enhanced appreciation for the scientific basis and advanced education required by speech language pathologists similarly led to discussion regarding minimal degree requirements for this profession. While not yet mandated, a doctorate in the field of speech language pathology would include similar foci to many OTD programs, such as advanced clinical practice, leadership, interdisciplinary work, and professional dissemination of information (Leslie, McNeil, Coyle, \& Messick, 2011).

\section{Clinical Doctorate and Current Trends}

Formal adoption of the Accreditation Standards for Doctoral-Degree-Level Education Program for the Occupational Therapist occurred in 2006. These standards became the first set of doctoral level stands in occupational therapy education, becoming effective in January of 2008 (ACOTE, 2017a). As with previous standards, the doctoral standards provided minimum requirements for educational programs, and were developed following open hearings, call for comments, and debates at national education meetings. This process aimed to be "open and collaborative to the various groups of stakeholders" (Dickerson \& Trujillo, 2009, p. 48) through offering multiple avenues and venues to voice support or concern regarding the proposed standards. Currently ACOTE standards for OTD education only apply to entry-level OTD programs; however, draft standards for post-professional programs will provide additional structure to postprofessional education in the future.

The AOTA Board of Directors, in a statement published in 2014, laid out a vision for the profession to advance to a clinical doctorate level of preparation as a mandate for entrylevel by the year 2025 (AOTA, 2014). Rationale for this decision included a variety of reasons, such as degree confusion between the variety of masters and doctoral degree designations currently present in the field (AOTA, 2014; Brown et al., 2015).

Additionally, focus on professional autonomy to meet the needs of practice settings, interprofessional practice, and increased need for scholarship relevant to clinical practice were also highlighted (Brown, Mu, \& Crabtree, 2006; Case-Smith, Page, Darragh, Rybski, \& Cleary, 2014).

Opponents to mandatory doctoral preparation have reported this transition will attract only a select group of potential students to the profession, limiting opportunities for increased diversity and hindering those with limited financial resources (Coppard \& 
Dickerson, 2007; Fisher \& Crabtree, 2009; Siler \& Randolph, 2006). These arguments leave many in favor of continuing dual entry-level degree requirements, allowing students to select the best degree to meet their unique needs. Despite this, others feel that mandatory doctoral preparation may lead to increased access to clients due to decreased need for referral for services (Siler \& Randolph, 2006).

Despite dialogue and recommendations within the profession, public knowledge of what differentiates an OTD from a master's degree or the differences between an entry-level and post-professional OTD may not fully be understood. Clinical or professional doctorates, "emphasize sophisticated practice competencies rather than research and knowledge production" (Pierce \& Peyton, 1999, p. 64). Mentored clinical experiences focusing on leadership and advanced practice competency are highlighted, over research, with the ultimate goal of developing autonomous practitioners that may assist in decreasing barriers to primary care service provision (Montoya \& Kimball, 2006). The clinical doctorate emerged as a method of meeting challenges presented in diverse and emerging clinical environments that research preparation alone could not provide. As Pierce and Peyton (1999) pointed out, clinical doctorates specific to a profession may serve to meet the unique needs of the profession through providing relevant skills to advance the field of occupational therapy.

Limited studies have conclusively determined implications for future practice based on entry-level degree requirements. An AOTA survey of 152 accredited entry-level master's programs indicated $81 \%$ (106 programs) reported plans to transition to an entry-level doctorate within 5 to 10 years (AOTA, 2015). Despite growing numbers of programs transitioning to accreditation at the doctoral level, a majority of occupational therapists historically have not been in favor of moving towards a required OTD for entry-level practice (Dickerson \& Trujillo, 2009; Smith, 2007). In spite of this, respondents did acknowledge that an OTD could increase career advancement and may lead to higher salaries, yet would likely not increase referrals for services or public recognition of the profession (Smith, 2007). While these studies provide important insights into perceptions regarding mandatory degree requirements, updated literature published within the last five years, which may provide a stronger view of current opinions, is limited.

Benefits of an OTD were cited in a 2006 post-graduation survey of graduates of the first OTD program in the nation. These included desire for increased clinical hands-on, practical skills, especially skills relevant to physical rehabilitation as the primary benefits of a clinical doctorate (Mu, Coppard, \& Padilla, 2006). These graduates reported that clinical skills were the most important aspect of practice for new graduates, citing future management and teaching experience depended on initial clinical opportunities. Overall, graduates reported positive perceptions of their OTD preparation and many reported transitioning to management roles within a year of clinical practice. A clinical doctorate may be an ideal opportunity to provide students rigorous experiences, especially for those desiring a future career in a clinical environment, versus a research based environment (Hinojosa, 2016). 
For the profession to "remain relevant, current, dynamic, and competitive, it must evolve" (Brown et al., 2015, p. 248). Emerging areas of practice have been identified for a number of years, and now a push for population, community-based, and occupationbased practice may require enriched educational and fieldwork preparation (Barrett, 2000). Within these settings complexity of patient needs, increased emphasis and need for evidence based practice, and need for stronger interprofessional collaboration for effective management of care coordination is evident (Case-Smith et al., 2014). These skills may be enhanced through completion of an OTD, an opportunity that many believe the profession must seize (Fisher \& Crabtree, 2009). This paper outlines a study determining the perceptions of occupational therapy students, clinicians, and educators concerning entry-level degree requirements.

\section{METHODS}

This study used a survey design with Likert scale items. The questionnaire provided an efficient means to collect a large sample of data from participants across the United States (Portney \& Watkins, 2009). The researchers disseminated the survey in November 2016, prior to the ACOTE mandate to move all entry-level degree programs to the doctoral-level. The researchers obtained institutional review board approval prior to dissemination of the survey.

\section{Participants}

Potential participants for this study included occupational therapy clinicians and academicians (occupational therapists and occupational therapy assistants) and occupational therapy students. The researchers recruited participants through the American Occupational Therapy Association OT Connections public and private forums. In addition, email requests to disseminate the survey information to all faculty and staff were sent to occupational therapy and occupational therapy assistant programs in the United States. To reach current practitioners, the survey was sent to state professional organization leaders from each state, with the request to disseminate to their membership. Follow-up postings and emails were sent two weeks after the initial request and the survey was closed one week later. Inclusion criteria required participants to be a current occupational therapy practitioner (clinician or educator) or student in an entry-level occupational therapy or occupational therapy assistant program.

\section{Instruments}

Data were gathered using a survey (see Appendix) created by the study investigators to assess perceptions of the entry-level OTD. Academic professionals in multiple fields reviewed an initial draft of the survey prior to use in this study to assess whether it answered the research question. The researchers created the final survey in PsychData and a survey link was provided to all potential participants. The survey was available for three weeks in the fall of 2016.

The initial items in the survey asked all participants to identify their primary role in the field of occupational therapy and the current geographic region where they were studying or practicing occupational therapy. States were divided into four regions 
(Northeast, Midwest, South, West) within the United States (See Table 1). Practitioners reported their highest degree earned and years of occupational therapy practice experience. Items on the survey asked students to provide what degree they were pursuing and to select a category that reflected their current progress within their professional program: didactic, Level II fieldwork, or doctoral experiential component. Additional items were directed at occupational therapy students to identify why they chose the program in which they were currently enrolled. Following the demographic section participants responded to 22 items on a 5-point Likert scale ranging from strongly disagree (1) to strongly agree (5).

Table 1

Division of States into Regions

\begin{tabular}{|l|l|l|l|}
\hline \multicolumn{4}{|c|}{ Region } \\
\hline Northeast & Midwest & South & West \\
\hline Connecticut & Illinois & Delaware & Arizona \\
Massachusetts & Indiana, & Florida & Colorado \\
New & Michigan & Georgia & Idaho \\
Hampshire & Ohio & Maryland & Montana \\
Maine & Wisconsin & North Carolina & Nevada \\
Rhode Island & lowa & South Carolina & New Mexico \\
Vermont & Kansas & Virginia & Utah \\
New Jersey & Minnesota & District of & Wyoming \\
New York & Missouri & Columbia & Alaska \\
Pennsylvania & Nebraska & West Virginia & California \\
& North Dakota & Alabama & Hawaii \\
& South Dakota & Kentucky & Washington \\
& & Mississippi & \\
& & Tennessee & \\
& & Arkansas & \\
& & Louisiana & \\
& & Oklahoma & \\
& & Texas & \\
& & & \\
& &
\end{tabular}

\section{Data analysis}

Researchers analyzed data using the Statistical Package for Social Sciences (SPSS) version 23.0 for Windows. These analyses included descriptive statistics for the demographic data and Likert scale responses, and Chi-square analysis to determine the relationships between the degree the occupational therapy student participant was pursuing and the reasons indicated for choosing that degree path. Further analyses utilized an ANOVA to identify if differences existed in responses on two scales based on key demographic data of degree earned, region, role type, and years of experience. Finally, researchers used independent t-tests to analyze response selection by component of student education and degree pursued by the occupational therapy students. 


\section{RESULTS}

A total of 419 completed surveys were returned. Of these, 31 did not have sufficient data to analyze or were clear duplicates, leaving a final $\mathrm{N}=388$ for analyses. Due to low reporting of respondents in the occupational therapy assistant practitioner, educator and student categories, the role types were collapsed into clinician, educator, and student. The category of clinical doctorate education and research doctorate were also collapsed due to low response rate from practitioners with a research doctorate.

Analyses of the demographic data indicated a greater response rate from the Northeast $(n=108)$ and Midwest $(n=116)$ regions of the country. The greatest number of responses were from occupational therapy students $(n=248)$ than any other role type category reported on the survey. Of the student responses, most students reported being in the didactic portion of their respective program $(n=189)$ and most were master level occupational therapy students $(n=157)$. Of the responses received from practitioners, the average years of practice was $22.22 \pm 12.52$. The greatest number of educator and clinician respondents held a bachelor's degree as the highest level of education $(n=45)$. See Table 2 for complete demographic data.

Table 2

Survey Demographics

\begin{tabular}{|l|r|r|}
\hline Characteristic & $\mathrm{n}$ & \multicolumn{1}{|c|}{$\%$} \\
\hline Primary role (N=388) & 45 & $11.6 \%$ \\
Clinician & 87 & $22.4 \%$ \\
Educator & 248 & $63.9 \%$ \\
Student & 8 & $2.1 \%$ \\
Not reported & 108 & \\
\hline Region of the United States (N=388) & $27.8 \%$ \\
Northeast & 116 & $29.9 \%$ \\
Midwest & 66 & $17.0 \%$ \\
South & 94 & $24.2 \%$ \\
West & 4 & $1.0 \%$ \\
Not reported & & \\
Practitioner/Educator - Highest degree earned $(\mathrm{n}=137)$ & 17 & $12.41 \%$ \\
Associate & 45 & $32.84 \%$ \\
Bachelor & 29 & $21.17 \%$ \\
Master & 28 & $20.44 \%$ \\
Doctorate & 18 & $13.14 \%$ \\
Not Reported & & \\
\hline Practitioner/Educator - Years of experience $(\mathrm{n}=137)$ & 32 & $23.36 \%$ \\
$0-10$ & 28 & $20.44 \%$ \\
$11-20$ & 38 & $27.74 \%$ \\
$21-30$ & 38 & $27.74 \%$ \\
$31+$ & 1 & $0.73 \%$ \\
\hline Not Reported & & \\
\hline
\end{tabular}




\begin{tabular}{|l|r|r|}
\hline Student - Current component of program $(\mathrm{n}=251)$ & & \\
Didactic & 204 & $81.27 \%$ \\
Level II Fieldwork & 43 & $17.13 \%$ \\
Doctoral Experiential Component & 1 & $0.40 \%$ \\
Not Reported & 3 & $1.2 \%$ \\
\hline Student - Degree pursuing $(\mathrm{n}=251)$ & & \\
Associate & 19 & $7.57 \%$ \\
Bachelor & 1 & $0.4 \%$ \\
Master & 174 & $69.32 \%$ \\
Entry-level Doctorate & 56 & $22.31 \%$ \\
Not Reported & 1 & $0.4 \%$ \\
\hline
\end{tabular}

Occupational therapy student participants were provided a list of 12 items and asked to select all items that were congruent with the reason(s) they chose to pursue their respective degree (master's or doctorate). A significant relationship was found between the student wanting their respective degree and choosing that degree path (masters: $\left.\chi^{2}(1)=92.892, p<0.001\right)$; doctorate: $\left.\left(\chi^{2}(1)=140.147, p<0.001\right)\right)$. Additional chi-square analyses were conducted to compare the frequency of selection of each item between master's and doctoral students. A significant relationship was also found for doctoral students to choose their degree more frequently than master's students based upon the desire for personal development $\left(\chi^{2}(1)=6.374, p=0.012\right)$, interest in research $\left(\chi^{2}(1)=8.691, p=0.003\right)$, desire to teach $\left(\chi^{2}(1)=26.547, p<0.001\right)$, experience with advanced practice $\left(\chi^{2}(1)=16.262, p<0.001\right)$, and trends in occupational therapy $\left(\chi^{2}(1)=11.766, p=0.001\right)$. A significant relationship was found for master's students to have chosen their degree more often because of cost $\left(\chi^{2}(1)=9.830, p=0.002\right)$.

The researchers collapsed the Likert scale items into two separate scales. The first scale, the Student Preparation for Practice (SPP) scale, compromised the first 10 Likert items. The scale ranged from a strongly disagree score of 10 to a strongly agree score of 50, with a neutral score of 30 . The second scale, the Impact on Occupational Therapy Practice (IOTP) scale, comprised the next eight survey items. This scale ranged from a strongly disagree score of 8 to a strongly agree score of 40 , with a neutral score of 24. Exploratory analyses were conducted to ensure the items met all assumptions for parametric testing. Internal consistency reliability standard was met for both scales. Cronbach's alpha for the SPP scale was 0.94 and the alpha for the IOTP scale was 0.88 . A Cronbach's alpha of greater than 0.70 indicates good internal consistency reliability.

Initial analyses identified the mean responses of all participants on the SPP and IOTP scales. The mean ranking for all participants on the SPP scale was $32.25 \pm 9.53$. This indicated a slightly above neutral response. The mean ranking for all participants on the IOTP scale was near neutral at $24.13 \pm 7.01$. 
Further analyses were conducted using ANOVA with the Bonferroni for all post-hoc testing for grouping by region of the US, role type, practitioner degree earned and practitioner years of experience. Note the use of the term practitioner refers to all licensed occupational therapy practitioners, both educators and clinicians. Independent samples t-test was completed for grouping of participants by student component of education and degree pursued by occupational therapy students (master and doctorate).

The researchers found significant differences between practitioners with different degrees on the IOTP scale and by role type on both the SPP and IOTP scales. On the SPP scale, results indicated significant differences between clinicians $(29.31 \pm 8.91)$ and students (33.51 \pm 9.32 ) and between student participants in the didactic portion $(34.05 \pm 9.05)$ versus the Level II Fieldwork portion $(30.53 \pm 10.41)$ of their program. On the IOTP scale the significant differences were found between practitioners with a master's degree $(25.21 \pm 8.42)$ and associate's degree $(17.24 \pm 5.40)$; doctorate degree $(23.25 \pm 7.12)$ and associate's degree (17.24 \pm 5.40$)$; educator $(22.49 \pm 7.87)$ and student $(25.51 \pm 6.47)$; clinician $(20.31 \pm 6.13)$ and student $(25.51 \pm 6.47)$; and students in a master's level program (23.81 \pm 6.91$)$ and entry-level doctorate program (30.77 \pm 4.09). Further analyses indicated no significant differences between groups based upon region of the country or years of experience for either scale. See Tables 4 and 5 for complete analysis results.

Table 4

Differences between Multiple Groups on the SPP and IOTP Scales

\begin{tabular}{|c|c|c|c|}
\hline & Mean \pm SD & $F(\mathrm{df})$ & $\mathrm{P}$ \\
\hline \multicolumn{4}{|c|}{ Student Preparation for Practice Scale } \\
\hline $\begin{array}{l}\text { Region of the U.S. } \\
\text { Northeast } \\
\text { Midwest } \\
\text { South } \\
\text { West }\end{array}$ & $\begin{array}{c}31.61 \pm 9.10 \\
32.83 \pm 9.37 \\
33.93 \pm 10.80 \\
30.99 \pm 9.29\end{array}$ & $1.446(3,358)$ & 0.229 \\
\hline $\begin{array}{l}\text { Role Type } \\
\text { Educator } \\
\text { Clinician } \\
\text { Student }\end{array}$ & $\begin{array}{l}31.01 \pm 9.74 \\
29.31 \pm 8.91 \\
33.51 \pm 9.32\end{array}$ & $4.980(2,356)$ & 0.007 \\
\hline $\begin{array}{l}\text { Practitioner Degree Earned } \\
\text { Associate } \\
\text { Bachelor } \\
\text { Master } \\
\text { Doctorate }\end{array}$ & $\begin{array}{c}25.65 \pm 7.04 \\
30.09 \pm 8.39 \\
33.21 \pm 11.09 \\
31.61 \pm 9.53\end{array}$ & $2.562(3,115)$ & 0.058 \\
\hline
\end{tabular}




\begin{tabular}{|c|c|c|c|}
\hline $\begin{array}{l}\text { Practitioner Years of Experience } \\
\quad 0-10 \\
11-20 \\
21-30 \\
31+\end{array}$ & $\begin{array}{c}31.19 \pm 8.57 \\
29.07 \pm 9.77 \\
32.24 \pm 10.57 \\
28.50 \pm 9.24\end{array}$ & $1.206(3,132)$ & 0.310 \\
\hline \multicolumn{4}{|c|}{ Impact on Occupational Therapy Practice Scale } \\
\hline $\begin{array}{l}\text { Region of the U.S. } \\
\text { Northeast } \\
\text { Midwest } \\
\text { South } \\
\text { West }\end{array}$ & $\begin{array}{l}22.89 \pm 7.26 \\
24.95 \pm 6.97 \\
25.32 \pm 7.25 \\
23.54 \pm 6.46\end{array}$ & $2.348(3,358)$ & 0.072 \\
\hline $\begin{array}{l}\text { Role Type } \\
\text { Educator } \\
\text { Clinician } \\
\text { Student }\end{array}$ & $\begin{array}{l}22.49 \pm 7.87 \\
20.31 \pm 6.13 \\
25.51 \pm 6.47\end{array}$ & $14.275(2,356)$ & $<0.001$ \\
\hline $\begin{array}{l}\text { Practitioner Degree Earned } \\
\text { Associate } \\
\text { Bachelor } \\
\text { Master } \\
\text { Doctorate }\end{array}$ & $\begin{array}{l}17.24 \pm 5.40 \\
21.11 \pm 6.55 \\
25.21 \pm 8.42 \\
23.25 \pm 7.11\end{array}$ & $5.132(3,115)$ & 0.002 \\
\hline $\begin{array}{l}\text { Practitioner Years of Experience } \\
\begin{array}{l}0-10 \\
11-20 \\
21-30 \\
31+\end{array}\end{array}$ & $\begin{array}{l}22.66 \pm 6.82 \\
20.04 \pm 7.83 \\
22.87 \pm 8.12 \\
21.45 \pm 6.43\end{array}$ & $0.986(3,132)$ & 0.401 \\
\hline
\end{tabular}


Table 5

Differences between Two Groups on the SPP and IOTP Scales

\begin{tabular}{|c|c|c|c|}
\hline & Mean \pm SD & $t(d f)$ & $\mathrm{P}$ \\
\hline \multicolumn{4}{|c|}{ Student Preparation for Practice Scale } \\
\hline $\begin{array}{l}\text { Component of Education } \\
\text { Didactic } \\
\text { Level II Fieldwork }\end{array}$ & $\begin{array}{l}34.05 \pm 9.05 \\
30.53 \pm 10.41\end{array}$ & $2.134(225)$ & 0.034 \\
\hline $\begin{array}{l}\text { Occupational Therapy Student } \\
\text { Degree } \\
\text { Master } \\
\text { Doctorate }\end{array}$ & $\begin{array}{l}30.94 \pm 8.79 \\
40.98 \pm 6.27\end{array}$ & $7.553(118.836)$ & $<0.001$ \\
\hline \multicolumn{4}{|c|}{ Impact on Occupational Therapy Practice Scale } \\
\hline $\begin{array}{l}\text { Component of Education } \\
\text { Didactic } \\
\text { Level II Fieldwork }\end{array}$ & $\begin{array}{l}25.79 \pm 6.29 \\
24.26 \pm 7.15\end{array}$ & $1.400(225)$ & 0.163 \\
\hline $\begin{array}{l}\text { Occupational Therapy Student } \\
\text { Degree } \\
\text { Master } \\
\text { Doctorate }\end{array}$ & $\begin{array}{l}23.81 \pm 6.19 \\
30.77 \pm 4.09\end{array}$ & $9.248(133.259)$ & $<0.001$ \\
\hline
\end{tabular}

The final item on the survey asked participants if the entry-level doctoral degree should (1) not be offered, (2) be offered but not required, or (3) be the required entry-level degree. A strong majority of participants reported that the entry-level doctoral degree should be offered but not required $(n=276,75 \%)$. Sixty-nine $(18.8 \%)$ of the participants reported the entry-level OTD should be the required entry-level degree and $23(6.3 \%)$ participants reported that it should not be offered.

\section{DISCUSSION}

The purpose of this study was to determine perceptions of entry-level degree requirements in occupational therapy. Overwhelmingly, respondents agreed that the profession should maintain dual entry into the profession. Only a small number of respondents felt the OTD should not be offered. In contrast, $68 \%$ of respondents in a 2009 study by Dickerson and Trujillo disagreed or strongly disagreed with the profession moving towards a single point of entry at the doctorate level. This variation among studies provided significant evidence to demonstrate a change in perception over the last eight years. Because only a small percentage of respondents in the current study felt the OTD should be mandatory, indicating that the rate of change in perception 
remains slower than other professional programs currently at the doctorate level. Results across geographic region were relatively similar, indicating overall consensus across the nation and supporting findings from a 2007 study conducted by Smith. Despite degree confusion being a topic of discussion within the profession (AOTA, 2014; Brown et al., 2015, Wells \& Crabtree, 2012), clinicians, educators, and students supported maintaining the current state of multiple degree offerings.

Degree type held among respondents played a factor in their perceptions of degree requirements, which has been observed in previous research (Brudvig \& Colbeck, 2007; Dickerson \& Trujillo, 2009). Clinicians and educators with associate's degrees, as compared to those with master's or doctoral degrees held different views regarding entry-level degree requirements. This highlighted the notion that respondents without a doctoral degree may be unfamiliar with the components and requirements of a clinical doctorate and thus unaware of how an advanced degree may influence not only individuals, but also the profession as a whole and to a larger extent society. Further, respondents holding a bachelor's degree may feel their own clinical experience produced higher qualifications than an advanced degree (Fisher \& Crabtree, 2009; Siler \& Randolph, 2006). For this reason, including students in this survey provided responses from those currently in the field that may have answered solely based on their own experiences, along with students just entering the profession.

A variety of rationale for selection of an OTD over a master's degree was found among student respondents. Among these, students indicated interest in research, desire to teach, personal development, and advanced practice as key indicators for their degree selection. These skills align with previous research findings that explored motivation for expanded knowledge (Barrett, 2000), enhanced research skills (Case-Smith et al., 2014) and ability to be more autonomous (Brudvig \& Colbeck, 2007). All groups of respondents overall agreed that students would be more prepared for practice as was the intent of one such doctoral program as reported by Case-Smith et al. (2014); however, the mean score $(32.25 \pm 9.53)$ in the student preparation for practice scale did trend more toward a neutral perception. As expected, cost attributed to students' decision not to pursue an OTD. This factor has been noted in the literature to be a cause of discouragement for some students, preventing them from pursuing a degree and potentially decreasing diversity within professions (Siler \& Randolph, 2006). Despite this, lack of diversity specifically within the profession of occupational therapy is a much more complex issue that transitioning to a doctoral mandate would likely not impact (Fisher \& Crabtree, 2009).

Students currently enrolled in the didactic, versus fieldwork portion of their curriculum, more strongly agreed that an OTD would prepare them for practice with a wide variety of skills. This finding could be due to students in a didactic setting having been surrounded with information related to theory, leadership, research, and administration, while those on fieldwork may have been exposed to more in vivo situations in which these skills were not as frequently incorporated into daily intervention. 
While discussion regarding benefits of the clinical doctorate is an ongoing and at times polarizing topic, professions that have previously transitioned to a doctoral degree, including physical therapy, have survived this change in degree requirements. Initial benefits to this transition within occupational therapy such as increased reimbursement for services, improved professional status, or third party reimbursement for primary care service delivery may not be widely observed initially (Siler \& Randolph, 2006), but other benefits may become more apparent. As more professional programs make this transition discussion involving multiple professions may be warranted to improve clarity of degree requirements and potentially propose uniform criteria (Siler \& Randolph, 2006), as currently exists with PhD programs. As professional clinical doctorate programs become more popular (Montoya \& Kimball, 2006) with programs including physical therapy, audiology, and others already mandating doctoral degrees, occupational therapy must aim to remain competitive with such programs through professional education mandated at a similar level (Brown, Mu, \& Crabtree, 2016). In fact, not doing so may lead to loss of quality potential candidates deciding to enter other professional programs (Fisher \& Crabtree, 2009).

\section{Limitations}

Despite a large number of respondents, there are limitations noted within this study. Survey design research holds inherent bias due to the nature of self-report of the participant's perceptions at the time of answering the survey items. Participants may not have responded truthfully or in response to what they felt met the purpose of this study (Portney \& Watkins, 2009). There is a limitation of potential voluntary response bias. Individuals who held a strong opinion for or against the entry-level OTD may have been more likely to participate in the survey (Portney \& Watkins, 2009). Voluntary survey completion among students may have represented those with strong opinions on the topic, creating bias towards these views based on the degree they were currently pursuing. Furthermore, practitioner participants with an OTD were not asked to identify if their degree was obtained as entry-level or post professional. The timing of the degree attainment may have influenced the participant's bias toward or against the entry-level OTD. Differentiating among highest level of education as an entry-level OTD versus post-professional may have provided additional insights and results. The high number of respondents who held a bachelor's degree is noted. It is unclear if this degree level influenced perceptions of higher education among these respondents; however, those with a bachelor's degree may have had decreased knowledge of the differences in master's and doctoral occupational therapy degrees.

Dissemination of this survey occurred through state organizations, OT Connections, and occupational therapy/ occupational therapy assistant programs in the United States.

Because of this, therapists who were not active in AOTA or their state organization may not have had access to the survey. This also limited the researchers' ability to determine the response rate. Further, a low response rate from students currently pursuing an occupational therapy assistant degree was observed. Due to this low response rate, authors were unable to adequately determine occupational therapy assistant student perceptions of the entry-level OTD. Overall, including students, educators, and clinicians was a strength of this study. 
The predominately neutral rankings on the IOPT scale aligned with what was currently observed within professional dialogue surrounding this topic. Findings from this survey can be strengthened by follow-up research that explores practitioners, educators, or students with strong opinions, for or against, the OTD versus those that hold neutral views. This research may be best captured utilizing qualitative methodology to strengthen overall findings and provide thematic analysis of these polar views. Finally, while survey data provides insight into respondents' views and perceptions, limitations inherently exist with this design. Among these, personal experiences were likely a factor in how respondents rated certain items.

\section{Implications for Occupational Therapy}

With recent revisions in mandatory entry-level requirements for occupational therapists, discussion of degree requirements remains timely. In fact, Fisher and Crabtree (2009) stated that discussion regarding transition to a clinical doctorate is a "worthy question" (p. 656). As the role of occupational therapists continues to expand in both traditional and non-traditional settings, new skills may be required in order to meet the demands of contemporary practice. Ensuring current and future clinicians, researchers, and educators can meet these demands and that occupational therapy students are adequately prepared to enter the workforce is of vital importance. Results of this study highlight implications for occupational therapy education to explore how these varied roles may be positively influenced by practitioners with a clinical doctorate. While advanced education offered from an OTD may provide these skills, research must be conducted that assists in demonstrating how significantly an OTD versus a master's degree will influence the profession or better prepare future therapists. Case examples describing doctoral capstone projects is warranted in future occupational therapy literature. With increasingly more OTD programs emerging, additional research is necessary that explores clinical preparation and public perceptions of the OTD.

The results of this study indicate there are differences in views regarding entry-level degree requirements among groups based upon role type (clinician, educator, student) and current degree earned. In order for the profession to move forward with a single entry degree, dialogue is necessary to discern what skills patients can expect and what level of competency is required from occupational therapists. Future research should address implications of a single point of entry degree requirement in occupational therapy education, comparing occupational therapy to other health science professions that have previously mandated doctoral preparation. These professions each have faced similar challenges from various groups within their profession, yet have overcome barriers following this transition (Brudvig \& Colbeck, 2007; Koehnke, Besing, SheaMiller, \& Martin, 2004).

Current and future students entering the profession must gain a broader understanding of how a doctoral degree will allow them to influence the future of the profession and to contribute to advanced clinical practice, advocacy, and education efforts. The purpose of the entry-level doctoral degree is to exceed current standards for the master's degree in "technology, program development, staff development, synthesis and practice of advanced knowledge, and demonstrated competency in clinical practice skills, research 
skills, administration, leadership, program and policy development, advocacy, education, or theory development" (AOTA Commission on Education, 2015, p. 3). To meet these aims, future research should include occupational therapy students and should focus on the degree to which doctoral projects and experiential learning aim to advance the profession and how these activities advance clinical practice and scholarship. Further, occupational therapy education programs must adapt to meet the needs of modern learners entering the profession (Fisher \& Crabtree, 2009).

\section{CONCLUSION}

This study suggests that the majority of occupational therapy practitioners, educators, and students surveyed are in favor of an optional entry-level OTD. A fewer number of respondents believe that the OTD should be required for entry-level competence. Most of those that responded do not believe that an entry-level doctorate will be more effective than a master's degree in helping students develop clinical practice skills, but they believe that it will help students further develop research skills. Further education among current occupational therapists regarding the benefits of an entry-level OTD would be beneficial as the profession moves towards the OTD mandated degree. Many health care professions have already transitioned to a doctoral-level single point of entry. It is important that as occupational therapy makes this transition, students, clinicians, and educators remain well informed on what this transition means for not only the profession, but also what implications may exist for recipients of occupational therapy services and for the healthcare system in general.

\section{References}

Accreditation Council for Occupational Therapy Education. (2012). 2011 Accreditation Council for Occupational Therapy Education (ACOTE®) standards. American Journal of Occupational Therapy, 66 (6 Suppl.), S6-S74. https://doi.org/10.5014/ajot.2012.66S6

Accreditation Council for Occupational Therapy Education. (2017a). Accreditation Manual. Retrieved from https://www.aota.org/ /media/Corporate/Files/EducationCareers/Accredit/Policies IACOTE\%20Manual\%20Complete.pdf

Accreditation Council for Occupational Therapy Education. (2017b). ACOTE 2027 mandate and FAQs. Retrieved from https://www.aota.org/EducationCareers/Accreditation/acote-doctoral-mandate-2027.aspx

American Occupational Therapy Association. (n.d.). Overview (ACOTE History, Meetings, Members). Retrieved from https://www.aota.org/EducationCareers/Accreditation/Overview.aspx

American Occupational Therapy Association. (2006). AOTA's centennial vision. Retrieved from http://www.aota.org/AboutAOTA/Centennial-Vision/Background.aspx

American Occupational Therapy Association. (2014). AOTA Board of Directors position statement on entry-level degree for the occupational therapist. OT Practice, 19(10), 18 - 21. 
American Occupational Therapy Association. (2015). Update on the entry-level degree for occupational therapist dialog. Retrieved from http://www.aota.org/AboutAOTA/Get-Involved/BOD/News/2015/update-entrylevel-degree-occupational-therapist-dialogue.aspx

American Occupational Therapy Association. (2016). Vision 2025. Retrieved from: www.aota.org/aboutaota/vision-2025.aspx

American Occupational Therapy Association Commission on Education. (2015). Frequently asked questions about the entry-level master's and doctoral degrees for occupational therapists. Retrieved from http://www.aota.org/ /media/Corporate/Files/EducationCareers/Educators/COE/F AQ-on-Professional-Entry-Degrees-2015.pdf

Andersen, L. T. \& Reed, K. L. (2017). The history of Occupational Therapy: The first century. Thorofare, $\mathrm{NJ}$ : Slack Inc.

Barrett, K. (2000). The time is now for innovative fieldwork and practice. Education Special Interest Section Quarterly, 2, 1-2.

Brown, T., Crabtree, J. L., Mu, K., \& Wells, J. (2015). The entry-level occupational therapy clinical doctorate: Advantages, challenges, and international issues to consider. Occupational Therapy in Health Care, 29(2), 240-251. https://dx.doi.org/10.3109/07380577.2015.1013597

Brown, T., Mu, K., \& Crabtree, J. L. (2006). The occupational therapy clinical doctorate: The next development in pre-registration occupational therapy education? British Journal of Occupational Therapy, 79(12), 725-726. https://doi.org/001:10.1177/03080226166681968196

Brudvig, T. J., \& Colbeck, C. L. (2007). The doctorate of physical therapy: Clinical and academic physical therapists' perception of appropriate curricular changes. Journal of Physical Therapy Education, 21(1), 3-13. https://doi.org/10.1097/00001416-200701000-00002

Case-Smith, J., Page, S. J., Darragh, A., Rybski, M., \& Cleary, D. (2014). The Issue Is The professional occupational therapy doctoral degree: Why do it? American Journal of Occupational Therapy, 68(2), e55-e60. https://doi.org/10.5014/ajot.2014.008805

Colman, W. (1992). Exploring educational boundaries: Occupational therapy and the multiple-entry-route system, 1970-1982. American Journal of Occupational Therapy, 46, 260-266. https://doi.org/10.5014/ajot.46.3.260

Coppard, B. M., \& Dickerson, A. (2007). A descriptive review of occupational therapy blueprint. American Journal of Occupational Therapy, 61(6), 672-677. https://doi.org/10.5014/ajot.61.6.672

Dickerson, A. E., \& Trujillo, L. (2009). Practitioners' perceptions of the occupational therapy clinical doctorate. Journal of Allied Health, 38(2), 47e-53e.

Fisher, T. F., \& Crabtree, J. L. (2009). The issue is - Generational cohort theory: Have we overlooked an important aspect of the entry-level occupational therapy doctorate debate? American Journal of Occupational Therapy, 63(5), 656-660. https://doi.org/10.5014/ajot.63.5.523

Griffiths, Y., \& Padilla, R. (2006) National status of the entry-level doctorate in occupational therapy (OTD). American Journal of Occupational Therapy, 60(5), 540-550. https://doi.org/10.5014/ajot.60.5.487 
Hinojosa, J. (2016). EPortfolio: The scholarly capstone for the practice doctoral degree in occupational therapy. The Open Journal of Occupational Therapy, 4(3). 10-16. https://doi.org/10.15453/2168-6408.1203

Koehnke, J., Besing, J., Shea-Miller, K., \& Martin, B. (2004). Seton Hall University doctor of science degree program: Clinical doctorate in audiology. American Journal of Audiology, 13(1), 9-15. https://doi.org/10.1044/1059-0889(2004/003)

Leslie, P., McNeil, M. R., Coyle, J., \& Messick, C. (2011). Clinical doctorate in speech language pathology. ASHA Leader, 16(9), 14-17. https://doi.org/10.1044/leader.FTR2.16092011.14

Montoya, I. D., \& Kimball, O. M. (2006). Marketing clinical doctorate programs. Journal of Allied Health, 36(2), 107-112.

Mu, K., Coppard, B., \& Padilla, R. (2006). Graduate outcomes of first entry-level occupational therapy doctoral program in the United States. Education Special Interest Section Quarterly, 16(1), 1-4.

Pierce, D., \& Peyton, C. (1999). A historical cross - disciplinary perspective on the professional doctorate in occupational therapy. American Journal of Occupational Therapy, 53(1), 64-71. https://doi.org/10.5014/ajot.53.1.7

Plack, M.M. \& Wong, C. J. (2002). The evolution of the doctorate of physical therapy: Moving beyond the controversy. Journal of Physical Therapy Education, 16(1), 48-59. https://doi.org/10.1097/00001416-200201000-00008

Portney, L. G., \& Watkins, M. P. (2009). Foundations of clinical research: Applications to practice ( $3^{\text {rd }}$ ed.). Upper Saddle River, NJ: Pearson.

Siler, W. L. \& Randolph, D.S. (2006). A clinical look at clinical doctorates. Chronical of Higher Education, 52(46), 58.

Smith, D. (2007). Perceptions by practicing occupational therapists of the clinical doctorate in occupational therapy. Journal of Allied Health, 36(3), 137-140.

Wells, J. K., \& Crabtree, J. L. (2012). Trends affecting entry level occupational therapy education in the United States of America and their probable global impact. The Indian Journal of Occupational Therapy, 44(3), 17-22. 


\section{APPENDIX}

\section{Entry-Level Occupational Therapist Doctorate Survey}

What is your primary role in the field of occupational therapy? Note, primary is considered to be more than 20 hours of your typical work week.

1. Occupational therapist educator

2. Occupational therapy assistant educator

3. Occupational therapist clinician

4. Occupational therapy assistant clinician

5. Occupational therapist student (OTS)

6. Occupational therapy assistant student (OTAS)

7. Other:

8. Prefer not to answer

In what region of the United States do you primarily practice or study occupational therapy?

1. Northeast (CT, ME, MA, NH, RI, VT, NJ, NY, PA)

2. Midwest (IL, IN, MI, OH, WI, IA, KS, MN, MO, NE, ND, SD)

3. South (DE, FL, GA, MD, NC, SC, VA, D.C., WV, AL, KY, MS, TN, AR, LA, OK, $\mathrm{TX})$

4. West (AZ, CO, ID, MT, NV, NM, UT, WY, AK, CA, HI, OR, WA)

5. Prefer not to answer

\section{PRACTITIONERS:}

How many years have you been practicing occupational therapy?

What is your highest level of education?

1. Associate's degree (OTA)

2. Bachelor's degree (OT, OTA)

3. Master's degree (OT)

4. Clinical doctorate (OTD, DrOT)

5. Research doctorate (PhD, EdD, Sc.D, etc.)

6. Prefer not to answer

7. Other: 
ENTRY-LEVEL STUDENTS:

Which component of your education are you currently completing?

1. Didactic (classroom/online)

2. Level II Fieldwork

3. Doctoral experiential component

4. Prefer not to answer

What degree are you currently pursuing?

1. Entry-level master's degree (OT)

2. Entry-level doctorate degree (OT)

3. Associate's degree (OTA)

4. Bachelor's degree (OTA)

5. Prefer not to answer

Why did you choose the program you are currently enrolled in? Select all that apply.

1. I want a doctoral degree

2. I want a master's degree

3. Personal development/Increase education

4. Cost

5. Interest in research

6. Location of program

7. Reputation of program

8. Only program I was accepted

9. Desire to teach in the future

10. Length of time commitment

11. Experience with advanced practice

12. Trends in occupational therapy

13. Other: 
For each of the following statements, mark the category (strongly disagree to strongly agree) that most closely relates to your perception about the entry-level occupational therapy doctorate degree (OTD).

\begin{tabular}{|c|c|c|c|c|c|}
\hline $\begin{array}{l}\text { As compared to a master's } \\
\text { degree, I believe an entry-level } \\
\text { OTD education better prepares } \\
\text { students for practice in the } \\
\text { following areas: }\end{array}$ & $\begin{array}{l}\text { Strongly } \\
\text { Disagree }\end{array}$ & Disagree & Neutral & Agree & $\begin{array}{l}\text { Strongly } \\
\text { Agree }\end{array}$ \\
\hline 1. Clinical practice skills & & & & & \\
\hline 2. Research skills & & & & & \\
\hline 3. Administration & & & & & \\
\hline 4. Leadership & & & & & \\
\hline 5. Program \& Policy developmen & & & & & \\
\hline $\begin{array}{l}\text { 6. Advocacy for the profession \& } \\
\text { clients }\end{array}$ & & & & & \\
\hline 7. Use of theory in practice & & & & & \\
\hline $\begin{array}{l}\text { 8. The demands of working as a } \\
\text { clinician. }\end{array}$ & & & & & \\
\hline $\begin{array}{l}\text { 9. The readiness to collaborativel } \\
\text { work with other healthcare } \\
\text { professionals as part of an } \\
\text { interdisciplinary team. }\end{array}$ & & & & & \\
\hline $\begin{array}{l}\text { 10. Being up-to-date in new or } \\
\text { innovative evidence-based } \\
\text { evaluations and treatment } \\
\text { interventions. }\end{array}$ & & & & & \\
\hline
\end{tabular}


For each of the following statements, mark the category (strongly disagree to strongly agree) that most closely relates to your perception about the entry-level occupational therapy doctorate degree.

\begin{tabular}{|c|c|c|c|c|c|}
\hline $\begin{array}{l}\text { In my opinion, an entry-level OTD } \\
\text { education will: }\end{array}$ & $\begin{array}{l}\text { Strongly } \\
\text { Disagree }\end{array}$ & Disagree & Neutral & Agree & $\begin{array}{l}\text { Strongly } \\
\text { Agree }\end{array}$ \\
\hline $\begin{array}{l}\text { 1. Allow occupational therapists to } \\
\text { stay professionally competitive } \\
\text { with other health disciplines. }\end{array}$ & & & & & \\
\hline $\begin{array}{l}\text { 2. Improve occupational } \\
\text { therapists' knowledge in the } \\
\text { provision of quality clinical } \\
\text { services. }\end{array}$ & & & & & \\
\hline $\begin{array}{l}\text { 3. Enhance professional } \\
\text { recognition of occupational } \\
\text { therapists among other health } \\
\text { care professionals. }\end{array}$ & & & & & \\
\hline $\begin{array}{l}\text { 4. Increase confusion among } \\
\text { clients related to differences } \\
\text { between a doctoral prepared OT } \\
\text { and a medical doctor. }\end{array}$ & & & & & \\
\hline $\begin{array}{l}\text { 6. Improve the client experience of } \\
\text { care. }\end{array}$ & & & & & \\
\hline 7. Improve the health of clients. & & & & & \\
\hline $\begin{array}{l}\text { 8. Reduce the cost of } \\
\text { occupational therapy services. }\end{array}$ & & & & & \\
\hline $\begin{array}{l}\text { 9. Discourage individuals from } \\
\text { entering the profession. }\end{array}$ & & & & & \\
\hline
\end{tabular}




\begin{tabular}{|l|l|}
\hline In my opinion, the entry-level OTD (select one): & \\
\hline Should not be offered & \\
\hline Should be offered but not required & \\
\hline Should be the required entry-level degree & \\
\hline Other (please specify) & \\
\hline
\end{tabular}

